University of Wollongong

Research Online

Faculty of Business - Papers (Archive)

Faculty of Business and Law

2013

An evaluation of the world's major airlines' technical and environmental performance

Amir Arjomandi

University of Wollongong, amira@uow.edu.au

Juergen Seufert

University of Wollongong, juergen@uow.edu.au

Follow this and additional works at: https://ro.uow.edu.au/buspapers

Part of the Business Commons

Research Online is the open access institutional repository for the University of Wollongong. For further information contact the UOW Library: research-pubs@uow.edu.au 


\title{
An evaluation of the world's major airlines' technical and environmental performance
}

\author{
Abstract \\ Abstract presented at the 26th European conference on operational research, 1-4 July 2013, Rome, Italy \\ Keywords \\ evaluation, environmental, performance, technical, airlines, major, world \\ Disciplines \\ Business

\section{Publication Details} \\ Arjomandi, A. \& Seufert, J. (2013). An evaluation of the world's major airlines' technical and environmental \\ performance. Euro-Informs: 26th European Conference on Operational Research Abstract Book (pp. \\ 357-357). Rome, Italy: University of Rome.
}

This conference paper is available at Research Online: https://ro.uow.edu.au/buspapers/199 
1 - Modeling decision processes of a green supply chain with regulation on energy saving level

Gang Xie, Academy of Mathematics and Systems Science, Chinese Academy of Sciences, Siyuan Building Room C510, No.55, Zhongguancun East Road, 100190, Beijing, China, gxie@amss.ac.cn

In this study, we analyze the impact of threshold value of energy saving level set by the policy maker on energy saving level and price set by green supply chains. Then, the decision of the policy maker and the coordination of a supply chain are investigated. The results suggest that both regulation and supply chain structure have significant impacts on energy savings and profits. From the observations, we can conclude vertical integration and coordination should be advocated if energy savings is urgent and regulation is implemented.

2 - An Evaluation of the World's Major Airlines' Technical and Environmental Performance

Amir Arjomandi, Economics, University of Wollongong, University of Wollongong, 2522, Wollongong, NSW, Australia, amira@uow.edu.au, Juergen Seufert

This study uses bootstrapped VRS-DEA models to examine environmental and technical efficiency of airlines. 48 world's major fullservice (FSCs) and low-cost carriers (LCCs) are chosen from six different IATA regions. Our results show that a large number of the most technical efficient airlines are from the region China and North Asia while many of the most environmental efficient airlines belong to the region Europe and Russia. We also found that although the number of environmentally-oriented FSCs is increasing over the time, LCCs can still be seen as more environmentally-oriented airlines.

3 - Financial Feasibility Analysis for Project Selection Pall Jensson, School of Science and Engineering, Reykjavik University, Menntavegi 1, 101, Reykjavik, Iceland, pallj@ru.is

The focus of project management has been on enhancing methods on how to run projects efficiently, on time and within budget. The preproject effort has often been neglected. In recent years more emphasis has been directed to this pre-project effort and methods of feasibility analysis tools have developed. One of the key components in feasibility analysis is a financial analysis aimed at assessing the profitability of a project and thus supporting the project selection and justification. This paper discusses these models and how they are used in project selection and project justification

\section{WD-69}

Wednesday, 14:30-16:00

R19-3

\section{Public/Nonprofit Supply Chains}

Stream: Stream of INFORMS Society for Public Programs, Service and Needs

Invited session

Chair: Mohammad Moshtari, University of Lugano, Switzerland, mohammad.moshtari@usi.ch

\section{1 - Designing Intervention Strategy for Public-Interest Goods}

Ece Zeliha Demirci, Industrial Engineering, Bilkent University, Bilkent University, Department of Industrial Engineering EA325, 06800, Ankara, Turkey, edemirci@bilkent.edu.tr, Nesim Erkip

The supply chain of a public-interest good (health-related products, energy efficient appliances, eco-consumables etc.) is generally subject to a central authority's intervention due to its remarkable societal value. The aim of the central authority is maximizing the social utility. In this study, we consider a system composed of a retailer and a central authority that regulates the system through direct investment and/or subsidies. Overall, we model the system via bi-level programming, characterize the optimal strategy and provide useful insights for the regulation of public-interest goods.
2 - Factors Influencing Collaboration Among International Humanitarian NGOs: An Empirical Analysis Mohammad Moshtari, University of Lugano, Switzerland, mohammad.moshtari@usi.ch

This paper empirically investigates the factors influencing horizontal collaboration performance among international NGOs conducting humanitarian operations, providing a systematic view of the drivers and impediments to collaboration. Theories and concepts from interorganizational relationships constitute the study's theoretical foundation. Data are collected through a web-survey of International NGOs in 25 countries, and I use structural equation modeling to examine the proposed hypotheses.

3 - Locating vulnerable temporary depots prior to a natural disaster

Anastasia Nikolaeva, Industrial and Systems Engeneering, SUNY at Buffalo, 11 Georgian Ln., \#7, 14221, Williamsville, NY, United States, aanikola@buffalo.edu, Rajan Batta, Jun Zhuang

This talk addresses the problem of temporary supply depot (SD) locations in anticipation of a natural disaster (e.g. hurricane). Vulnerability of SDs is mentioned in previous works. We develop this line of work by modeling the assignment of protection levels to SDs that will decrease their chance to be affected by the disaster. We also consider vulnerability of route segments involved in supply distribution between SDs and DPs (demand points) by applying some ideas from the Influence Maximization literature. Numerical examples will be presented to contrast with existing models.

\section{WD-71}

Wednesday, 14:30-16:00

R16-1

\section{Health Care Management (Emergency Care/Services)}

\section{Stream: Health Care Management Invited session}

Chair: John Fowler, Industrial Engineering, Arizona State University, Tempe, AZ, United States, john.fowler@asu.edu

\section{1 - Optimal Control Policies for Ambulance Diversion} Esma Gel, School of Computing, Informatics and Decision Systems Engineering, Arizona State University, 699 S. Mill Avenue, 85281, Tempe, AZ, United States, esma.gel@asu.edu, Ahmet Hafizoglu, Adrian Ramirez Nafarrate, John Fowler

We consider optimal ambulance diversion control policies with the objective of minimizing patients' waiting time higher than a recommended safety time threshold. We model the problem using a Markov decision process formulation, and characterize the structure of an optimal ambulance diversion policy. We compare the performance of the optimal policy with simple heuristics using a simulation model, and analyze the value of information in ambulance diversion decisions.

\section{2 - DES modeling of an EMS call center}

Geert-Jan Kommer, Dept for Public Health Forecasting,

Dutch National Institute for Public Health and the

Environment, PO Box 1, Ant. van Leeuwenhoeklaan 9, 3720

BA, Bilthoven, Netherlands, geertjan.kommer@rivm.nl

Each year, the Ambulance Care Dispatch Centres in the Netherlands handle more than a million calls. Ambulance organisations respond to more than $1.000,000$ call-outs, $66 \%$ of which are urgent. These involve situations that may be life-threatening or may result in serious damage to health. The other $34 \%$ of call-outs involve planned transport. The ambulance care dispatch centres handle urgent calls from the national 112-emergency number and, via a different incoming line, requests from the police, general practitioners or other health care providers. Apart from handling the incoming calls, the di 